\title{
IMAGEM E OLHAR: PROCEDIMENTOS ECFRÁSTICOS EM POEMAS DE NÃO É CERTO ESTE DIZER
}

Mariana Neto Silva

Andrade*

\author{
*mariana.and@hotmail.com \\ Mestre em Estudos de Literatura, subárea Literatura \\ Portuguesa e Literaturas de Língua Portuguesa, pela \\ Universidade Federal Fluminense (UFF).
}

RESUMO: A partir da apresentação da premissa de Horácio, ut pictura poesis, e do conceito de ekphrasis objetivo analisar alguns poemas da obra Não é certo este dizer, publicada pelo poeta contemporâneo português João Miguel Fernandes Jorge em 1997.

PALAVRAS-CHAVE: Ecfrase; Literatura Portuguesa Contemporânea; João Miguel Fernandes Jorge.
ABSTRACT: From the presentation of the Horace's motto, ut pictura poesis, and of the concept of ekphrasis, I intend to analyze a few poems of the book Não é certo este dizer, published in 1997. His author is the Portuguese contemporaneous poet João Miguel Fernandes Jorge.

KEYWORDS: Ekphrasis; Contemporary Portuguese Literature; João Miguel Fernandes Jorge. 
Em que consiste uma imagem num poema? Ao considerar-se esta pergunta, poderíamos admitir que tal imagem faria com que o poema se tornasse também numa nova imagem. De imediato ocorreria a do espelho. Acabariamos por conceber mesmo que uma estava na outra e daqui resultava o sentido de ambas. Mas importa não esquecer que existe uma diferença essencial. É que a segunda imagem, no caso que referimos, não se encontra efetivamente no poema. Foi utilizada ape nas para representar o modo como a primeira nele estava. Se ela se encontrasse no poema, este passava a ser outro. Ora é isso o que acontece sempre em poesia, mesmo que não se recorra a esta segunda imagem.

Fernando Guimarães.

In: Revista Relâmpago, ano XII, número 23, 2008

Seria extremamente difícil precisar quando, na história da Arte ocidental, as noções de palavra e imagem se imbricaram, em manifestações que dialogam com estratos tanto do campo visual quanto do campo literário. Na verdade, ta fato se verifica ao pensarmos que as produções artísticas, de certa forma, têm um limbo comum; compartilham temas, sensações e anseios os quais o homem busca externar e servem-se, apenas, de instrumentos diferentes para expor essas interioridades. Do mesmo modo, seu modo de dizê-las é variado, em função do modo de concepção artístico por detrás da forma de uma obra de arte. Música, poema e escultura, por exemplo, poderão abordar uma mesma temática, e, nesse sentido, terão um elemento comum que as ligará; por outro lado, suas abordagens serão diferenciadas, por ser o material de uma o sonoro, de outra o signo, e da terceira o elemento palpável no qual foi modelada a estátua. Certamente, a perspectiva dos autores de cada obra são por si só distintas, e por isso produções de um mesmo campo, como a literatura, por exemplo, guardarão suas nuances particulares, ainda que focalizem o mesmo tema. Mais: ainda que tivéssemos duas produções distintas do mesmo autor, e com seus focos nas mesmas questões, não se poderia dizer que se trata de um único trabalho, pois, a cada vez que a arte é revisitada, novos produtos ela certamente dará e trará Porém, o que se discute aqui é essa natureza diferenciada das possibilidades de criação artística; e, se é certo que música, poema e escultura são variados modos de dizer que, com suas estratégias próprias, alcançam de um ou outro modo o leitor, todos eles, por seu impacto e pela recepção que estimulam no espectador, concorrem para aquele objetivo maior, já discutido por um dos maiores filósofos gregos, o qual é a catarse. Com efeito, Aristóteles - pois a ele aqui me refiro -, em sua Arte Poética, mensura as qualidades artísticas de comédia, epopeia e tragédia, considerando esta última como sendo, possivelmente, a mais nobre das três, pela significação e importância dos sentimentos humanos pela mesma enquadrados, valorosos ou não, e, também, por sua capacidade de, na abordagem de tais emoções, mobilizar o leitor.

A tragédia é a imitação de uma ação importante e completa, de certa extensão; deve ser composta num estilo tornado agra- 
1. ARISTÓTELES. Arte poética, p. 8. dável pelo emprego separado de cada uma das suas formas; na tragédia, a ação é apresentada, não com a ajuda de uma narrativa, mas por atores. Suscitando a compaixão e o terror, a tragédia tem por efeito obter a purgação dessas emoções. ${ }^{1}$

Notar que o conceito primordial da catarse já fora imaginado desde a Antiguidade não nos causa surpresa, ainda mais ao lembrarmo-nos de que a Grécia é o país-berço da Filosofia, comumente conhecida como mãe de todas as outras ciências do conhecimento. Entretanto, o fato de estarmos familiarizados com essa premissa não nos deve retirar a positiva impressão de que, já naquele tempo, a Arte, em suas mais variadas formas, era discutida e formalizada por meio de noções básicas - uso o termo não no sentido de noções simplórias, e sim no de gerais e norteadoras - que, mesmo hoje, perduram, e com força vigorosa. Basta pensarmos, por exemplo, na trajetória da catarse aristotélica por todo o desenvolvimento da teoria artística ocidental, até o século XX e, neste, Walter Benjamin; não seria a aura benjaminiana um processo similar ao catártico, no qual o estar defronte à obra de arte nos mobiliza de forma única - e, por isso mesmo, o autor tanto temia pela reprodutibilidade técnica, que, pela transmissão massiva, retiraria da arte o seu caráter singular, o peso do contato presencial entre espectador e obra; retiraria, em suma, o seu traço aurático?
Mesmo na reprodução mais perfeita, um elemento está ausente: o aqui e agora da obra de arte, sua existência única, no lugar em que ela se encontra. É nessa existência única, e somente nela, que se desdobra a história da obra. Essa história compreende não apenas as transformações que ela sofreu, com a passagem do tempo, em sua estrutura física, como as relações de propriedade em que ela ingressou. [...] O conceito de aura permite resumir essas características: o que se atrofia na era da reprodutibilidade técnica da obra de arte é sua aura. Esse processo é sintomático, e sua significação vai muito além da esfera da arte. Generalizando, podemos dizer que a técnica da reprodução destaca do domínio da tradição o objeto reproduzido. Na medida em que ela multiplica a reprodução, substitui a existência única da obra por uma existência serial. E, na medida em que essa técnica permite à reprodução vir ao encontro do espectador, em todas as situações, ela atualiza o objeto reproduzido. Esses dois processos resultam num violento abalo da tradição, que constitui o reverso da crise atual e a renovação da humanidade. ${ }^{2}$

O exemplo de Aristóteles reforça, justamente, a constante e já antiga preocupação do homem em entender e classificar os procedimentos artísticos, por um lado, e a ancestralidade e ao mesmo tempo permanência de tais questões nos cenários histórico e filosófico ocidentais. No mesmo sentido, há outra Arte Poética, além da aristotélica, que, tendo lançado uma premissa extremamente conhecida e divulgada, igualmente pontua questões ancestrais e também atuais no campo da
2. BENJAMIN. A obra de arte na era de sua reprodutibilidade técnica, p. 167-169. 
arte, sobretudo na frequentemente repensada relação entre a literatura e a pintura, ou, de forma ainda mais precisa, entre o signo e a imagem. Refiro-me à Arte Poética, obra redigida por Horácio por volta de 20 a.C., romano e também filósofo - pertencendo, portanto, àquele limbo comum que é a cultura greco-romana Antiga -, e a sua sentença latina ut pictura poesis, a qual pode ser traduzida por como a pintura é a poesia. A frase soa como bastante clara em sua pretensão: relacionar palavra e pictórico a tal ponto que a poesia poderia ser explicitamente lida como uma correspondência exata de um referente imagético externo ao próprio texto. $\mathrm{E}$, da mesma forma como a catarse ecoa em estudos das diferentes ramificações do literário, influenciando, por exemplo, a teoria da recepção, tópico relevante no âmbito da Teoria Literária, também o conceito horaciano motivou e gerou discussões teóricas de significativa importância, especialmente quando se pensa em trabalhos intersemióticos, ou em pesquisas que dependam de uma definição dessa fronteira entre distintos modos artísticos. Quando Horácio afirma a comparação entre pintura e poesia, iguala também procedimentos e modos de dizer; gera uma simbiose na qual a redação é a materialização idiomática, ou linguística, daquilo que é similarmente transmitido por intermédio da composição de figuras e imagens, isto é, do visual. O tópico, à semelhança das noções aristotélicas, e conforme já dito, permanece até os dias atuais, sendo possível vislumbrá-lo, por exemplo, nas concepções teóricas que estimularam o surgimento da chamada poesia concreta, a qual tem em Guillaume Apollinaire um de seus mentores e, também, mais significativos representantes. Tal vertente procura conceber a poesia não só por seu viés temático ou semântico, mas considerá-la, em contrapartida, como estrutura visual possível não só a fim de reforçar certa ideia que o autor deseja ver comunicada, mas inclusive a fim de formar pelo significante, pela forma material que é a palavra, uma composição imagética. O vocábulo é também símbolo e, nesse sentido, imagem - e a disposição dos verbetes pelo papel, que é para o escritor como a tela para o pintor, concorre para uma poesia que se torna, como Horácio enunciou, como a pintura. $\mathrm{O}$ famoso poema $A$ chuva - em francês, Il pleut-, de Apollinaire, é um bom representante da poesia concreta, e demonstra como, na ordenação dos versos em forma de gotas que se desprendem da nuvem e alcançam o chão, pela palavra se compõe um modelo pictórico.

Talvez seja interessante relembrarmos o fato de que o problema da aproximação entre artes se configura como muito mais crítico nos dias atuais, nos quais as manifestações artísticas se dissociaram de forma mais acentuada, o que levou, inclusive, a certa rivalidade, ou hierarquização, entre uma e outra forma de expressão. As concepções mais antigas acerca da arte - e incluímos as Artes Poéticas, tanto a de Aristóteles quanto a de Horácio - pressupunham forte 
3. CONRADO. Ekphrasis $e$ Bildgedicht: processos
ekphrásticos nas Metamorfoses de Jorge de Sena, p. 25. ligação entre produções artísticas de diferentes gêneses, supondo, eventualmente, certa indissociação entre as mesmas.

Desde que o homem começou a produzir "obras de arte", que por motivos religiosos, quer mágicos, quer de ordem meramen te estética, as artes estiveram mais ou menos associadas umas às outras e todas elas à vida humana num determinado contexto cultural.

Para Aristóteles seria impensável criar teorias independentes para a tragédia, a poesia e a música, porque elas eram inseparáveis na prática, e assim foi durante muitos séculos e em várias culturas muito diferentes. $O$ processo institucional de isolar as várias disciplinas em departamentos segundo os media e técnicas diferentes, normalizando-as individualmente, é relativament recente na história das artes, tendo criado situações incômodas de rivalidade entre as artes (embora a questão da primazia já seja anterior ao "ut pictura poesis") ou de impasse devido à criação de rígidas fronteiras, pois desde o advento do homo sapiens que arte, religião, tecnologias e meios de comunicação escrita estiveram estreitamente ligados e até interdependentes.

Perante tal concepção do fazer artístico, usual no período supracitado, torna-se mais fácil compreender a linha de pensamento que fomentou ideias-chave como a de ut pic tura poesis - uma correspondência plena e possível entre a palavra e a imagem, materiais diversos que comunicam, em suas especificidades, uma mensagem a ser passada a ponto de serem uma espelho da outra; ou uma similar à outra para usarmos a mesma nomenclatura pela qual seu primeiro enunciador optou. E, se é verdade que o trânsito inter-artes é verificável desde os tempos da Antiguidade - tanto que a teorização artística diagnostica e acompanha essa tendência conceituando conjuntamente movimentos estéticos distintos, sejam do campo da música ou da tragédia, por exemplo -, também é já nesse período historicamente demarcado que irrompe outra noção fulcral para os estudos literários, a qua se aproxima, por sua proposta, intimamente da proposição horaciana. Refiro-me à ekphrasis, conceito que, visto sob sua perspectiva clássica e tradicionalista, poderia ser traduzido, ou descrito, como a "representação verbal de um texto real ou fictício composto num sistema sígnico não-verbal" (CLÜVER apud CONRADO, 1996:28). A ideia do que seria ekphrasis - ou, para usar o termo aportuguesado, ecfrase - é frequentemente esclarecida por aquele que igualmente é o mais famoso dos exemplos encontrados na Antiguidade do uso de tal estratégia. A longa passagem da Iliada na qual ocorre a menção ao escudo de Aquiles ilustra de forma clara o processo ecfrástico: o armamento é apresentado de modo a possibilitar que o leitor construa, em sua mente, uma perfeita visualização do mesmo. A noção clássica de ekphrasis liga-se fortemente ao estatuto de pura descrição, sem permitir que o texto abra espaços para campos de subjetividade, além da 
própria representação escrita de um referente pictórico e/ou não-verbal; e é indiferente o fato de o objeto a ser descrito ser real ou não, pois o que importa é a potencialidade de visualização que o texto, regido sob o preceito da ecfrase, viabiliza.

Sólido forma o escudo, ornado e vário

De orla alvíssima e triple, donde argênteo Boldrié pende, e lâminas tem cinco.

Com dedáleo primor, divino engenho, Insculpiu nele os céus e o mar e a terra; Nele as constelações, do pólo engastes,

Oríon valente, as Híadas, as Pleias,

A Ursa que o vulgo denomina Plaustro, A só que não se lava no Oceano.

\section{$[\ldots]$}

Insculpiu loura messe, e dos ceifeiros Foice a talha afiada: em linha os molhos Por terra vão caindo; enfeixadores Seguem três para atá-los, e uns meninos Lestos atrás colhendo, os acumulam.

Numa paveia, o rei ceptrado assiste, Silente e alegre; à sombra de um carvalho Arautos põem-lhe a mesa, espostejada Enorme rês; mulheres aos ceifeiros
Se é certo dizer que a ekphrasis, bem como o ut pictura poesis de Horácio - e muitas vezes a tal sentença associada -, permaneceu como tópico aberto de discussão, também é verídico afirmar que nos últimos tempos, sobretudo a partir de meados do século XIX, e com maior ênfase nos movimentos geridos no século XX, aquela foi revista e reinventada por intermédio de novos e contemporâneos procedimentos ecfrásticos, o que indicia, a um só tempo, tanto uma certa bagagem, solidificada no antigo, e portanto tradicional, conceito que a ekphrasis clássica é, quanto um anseio de desconstrução, ou revitalização, que conduz a uma necessidade de se repensar o mesmo conceito, ou de se re-enunciá-lo, tendo em vista as dicções da produção poética recente. Fato é que a nova ecfrase já não constitui, unicamente, uma representação verbal daquilo que é não-verbal; tal palavra, embora certamente válida para a classificação de determinado método praticado em textos antigos - dos quais o excerto da Iliada, do qual foi acima transcrito um breve trecho, é um bom exemplo -, revela-se limitadora perante a gama de feituras contemporâneas baseadas na ecfrase. E a questão do representar igualmente se torna restrita quando pensamos não só na variedade e nos diferentes resultados obtidos por autores que, atualmente, lidam com o estilo ecfrástico, mas também quando verificamos que, ao menos para boa parte dos literatos, a ecfrase não apenas se manifesta como um ato de quem descreve ou reproduz, porém como um movimento

EM TESE

BELO HORIZONTE

v. 19 

5. CONRADO. Ekphrasis $e$ Bildgedicht: processos ekphrásticos nas Metamorfoses de Jorge de Sena, p. 24.

que pode partir para pontos de maior expansão. Claus Clüver diagnostica tal problema na enunciação e propõe uma nova definição para a ecfrase, identificando a mesma como "a verbalização de textos reais ou fictícios compostos num sistema sígnico não-verbal" (Apud CONRADO, 1996:28). O uso do termo verbalização liberta a ecfrase de uma condição restrita, e, sem deixar de englobar a ideia clássica, classifica com maior precisão a ideia contemporânea do conceito, cuja carência na sua delimitação já era sentida.

[...] a palavra ekphrasis passou a ser muito usada, mas frequentemente de forma pouco consistente, havendo uma certa dificuldade em chegar a um consenso sobre a melhor e mais operativa definição do conceito de modo a corresponder à diversidade de processos ekphrásticos da atualidade.

Devido à rápida e perturbadora evolução estética do século $\mathrm{XX}$, tanto no campo da literatura como no das outras artes, os contornos do processo ekphrástico estão constantemente ser postos em causa pelo contexto literário e visual dos nossos dias, e através de estudos e de controvérsias entre especialistas. Esta é razão suficiente para o interesse que desperta, no sentido de acompanhar a evolução da prática poética com uma atualização e um alargamento da extensão do conceito. ${ }^{5}$

Um exemplo de trabalho diferenciado com a ecfrase encontra-se na produção poética de João Miguel Fernandes Jorge, autor português, ainda hoje em atividade. Também autor de textos em prosa e de trabalhos de crítica literária, estreia em poesia com Sob sobre voz, de 1971, e é profundamente marcado por uma tendência à narratividade, visível nas poesias que elabora, e também por um exercício do olhar sobre lugares e coisas, o que igualmente transparece em diversos momentos de sua poemática.

Certos pontos da carreira de João Miguel Fernandes Jorge são bons indícios, senão ilustrativos, de sua inclinação para uma dicção poética diferenciada e, mais, de uma postura reflexiva acerca da própria função da poesia e de seus estatutos teóricos. Bastaria dizer que ele foi um dos participantes do movimento conhecido como Cartucho, cujo ato mais emblemático - e pelo qual foi polemicamente marcado, ato este rememorado até hoje - consistiu na transcrição de poesias variadas, redigidas pelos autores portugueses integrados ao movimento, em folhas avulsas de papel, as quais foram amassadas e depositadas em uma espécie de pacote ou sacola. A conotação simbólica de tal atitude não passou despercebida aos olhos dos críticos literários da época, que, por vias diversas, tentaram intuir a exata significação do gesto. O recipiente no qual a poesia fora colocada poderia ser visto como uma sacola de lixo - o que parecia ser enfatizado pelo amassamento das folhas, que continham os poemas, nele inseridas -, e então os ativistas do Cartucho estariam relegando a literatura a um lugar inferior, secundário, ou 
mesmo descartável, em uma realidade contemporânea avessa a manifestações poéticas; em outro sentido, o mesmo recipiente poderia ser encarado como uma embalagem, o que elevaria seu conteúdo ao status de presente, regalo para os dadivados que dele se servissem; e houve mesmo quem relacionasse o invólucro, por seu formato, ao saco escrotal, e desenvolvesse leituras interpretativas regidas por essa concepção. Seja qual for a significação escolhida, fato é que a ação adotada pelo grupo revela ousadia, originalidade e, sobretudo, uma sólida e diferencial postura de questionamento diante da poesia e de seu lugar dentro da vivência atual. Ter João Miguel Fernandes Jorge incluído em um coletivo com tal intencionalidade reforça sua predisposição a ocupar lugares não estratificados na literatura contemporânea, pois, ao apresentar sua produção poética em um modelo distinto do tradicional, que é o livro ou, quando muito, a publicação em alguma revista ou periódico, o autor desestabiliza noções pré-concebidas a respeito do seu próprio material de trabalho e subverte, por assim dizer, possíveis expectativas. A mesma tendência a uma dicção poética diferencial transparece no título de uma relativamente recente obra de Fernandes Jorge, Não é certo este dizer, publicada em 1997. Se considerarmos o pronome demonstrativo este, contido no título, como tendo por referente a própria coletânea de poemas, surge mais uma vez a noção de um dizer inovador e não tradicional - incorreto, portanto, quando comparado a um dizer mais usual e frequente, considerado padrão e, por extensão, lícito e correto. O dizer de João Miguel Fernandes Jorge se anuncia, desde o nome atribuído pelo mesmo a sua obra, como atípico; e, acerca tanto de escritor quanto de obra, Edgard Pereira registrará, na revista Colóquio Letras, que

[o livro] constitui o seu vigésimo livro de poesia, na sequência de um extenso e variado trabalho, atravessado por citações e marcas culturais, e que é referência obrigatória para a compreensão da produção poética portuguesa das três últimas décadas.

Resultado deste rico trajeto, o texto, com uma ambiguidade e flutuações de sentido possibilitadas pela descontinuidade e pela ironia, revela uma certa fluidez entre o rigor herdado dos anos 60 e a narratividade dos anos 80 . O fascínio pelas ruínas e escombros tanto da história coletiva como da desolada memória individual associa-se, neste livro, a uma imprecisa e onipresente melancolia, "esse triste fluir a que se chama memória", num discurso ironicamente próximo das modulações notariais da linguagem, ressaltando o aspecto solene e a "quase banalidade dos feitos" do passado. ${ }^{6}$

Um olhar sobre os poemas de Não é certo este dizer revela-nos a presença de um trabalho constante com a ecfrase; não a tradicional, restrita à representação de itens reais ou fictícios, mas justamente a sua versão contemporânea, aquela que Clüver preferiu denominar por meio do uso do expressivo termo verbalização, e que se verifica, na feitura literária, em textos que
6. PEREIRA. Recensão crítica a Não é certo este dizer, p. 312. 
trabalham com a estratégia ecfrástica em um índice além da mera descrição. No caso específico dos textos encontrados na referida obra, a ecfrase surge, em muitos, como ponto inicial, do qual decorrem digressões e reflexões tecidas pelo poeta, estas motivadas, ou desabrochadas, pela (na) imagem ou cena que de modo ecfrástico nos foi comunicada em um primeiro movimento do poema. Dá-se, assim, uma superposição de planos, sendo o primeiro regido por essa autonomia da imagem, desse cenário a princípio exposto e descrito; em seguida, o olhar do poeta se debruça por sobre a imagem, nela vislumbrando, muitas vezes por meio de detalhes, desejos ou angústias - sentimentos revelados por pequenos gestos e deduzidos a partir de elementos que a ecfrase outrora proporcionara. Rememorando mais uma vez a terminologia de Clüver, por mim citada há pouco, é lícito dizer que João Miguel Fernandes Jorge verbaliza os extratos pictóricos os quais anseia também nos fazer visualizar. Sua transmutação, para a linguagem literária, de um correspondente imagético externo ao texto, não importando se esse é verídico ou fictício, proporciona a feitura de poemas nos quais o descritivo, ou a representação - em suma, o ecfrástico, em seu sentido imediato -, concorrem para a composição de relatos impregnados de subjetividade, seja pela interpretação, obtida mediante o olhar do escritor, de um determinado fato ou da ação de alguém no poema descrito em dada cena, seja simplesmente pela atmosfera construída textualmente, e a impressão por esta transmitida. Com efeito, a seleção vocabular contribui para que, mesmo nos pontos de restrita descrição, o poema nunca esteja isento de uma significação maior, nele imbuída. S. Vicente - assim grafado pelo autor, com a abreviação que aqui reproduzo - é um poema breve, se considerarmos o tamanho de outros contidos na obra, e ilustra bem a sobreposição de planos, bem como o uso diferencial da ecfrase, a que foram aqui aludidos.

Lá fora tinha escurecido. Em plena vila temos a sensação de que estamos dentro de uma grande sala. Uma cortina de arbustos mantém-nos semi-ocultos. Do vale de sombras cavado em casas, apenas alumiado pelo tremeluzir dos candeeiros, ergue-se a vila, a vila de $S$. Vicente.

As janelas projectam sobre a praça

o desenho das vidraças. Tem palmeiras o

cemitério. Na parede da igreja

vislumbra-se o pulsar da ponta

de um cigarro. E o ar da noite desce

arrefeceu no verde

das serras em redor.

O pulso iluminado

pela chama do cigarro aproxima-se

procura alguém nesse escuro início da noite

para dizer, somente, um último, um primeiro adeus.
7. JORGE Não é certo este dizer, 27 
A instância melancólica, a qual Edgard Pereira faz menção, nos é transmitida, por exemplo, pela antinomia proposta entre "lá fora" e um aqui, isolamento reforçado pelos elementos da natureza que cercam a localidade e lhe dão certo invólucro de mistério, ou misticismo, pois é de um "vale de sombras", enredada por arbustos que a ocultam, apenas sob a luz difusa dos candeeiros acesos à porta das casas, que a vila ergue-se - verbo sintomático, que acusa os contornos mágicos dessa aparição, reforçando-a, ao mesmo tempo. A única luz dotada de alguma nitidez que surgirá será a de um cigarro, cuja mão que o segura representa, metonimicamente, um alguém à procura de outro alguém, seu semelhante, para enunciar um adeus primeiro e derradeiro. Principalmente nos primeiros versos do poema, a ecfrase é facilmente identificada: é por meio da descrição efetuada pelo poeta que conseguimos visualizar a composição geográfica da vila, e, logicamente, a seleção vocabular e o modo de dizer do autor foram fundamentais para, nessa representação, construir a aura mística que gera em nós, leitores, uma impressão diferenciada acerca de que lugar é este e de que atmosfera o encobre. No entanto, a aparição do "pulso iluminado" altera o ritmo do poema, que deixa de meramente apresentar a vila para enquadrar um in divíduo e, com este, uma carga subjetiva e profunda de isolamento e solidão. Acerca desse segundo momento do poema, cabem duas colocações importantes. Primeiro: formalmente, podemos notar que o texto conduz a essa evolução de um momento a outro; do exterior para o interior; do coletivo, que é a vila e suas casas, para o particularizado, na figura do fumante; em suma, esse zoom é visível tanto no deslocamento do olhar ao longo do poema - pois o autor ordena a sua apresentação do lugar e da cena de modo a estimular a sensação de progressivo foco - como na própria pontuação, a qual se acelera, dinamiza, à medida que o poema encontra seu clímax, e seu final, na proposição do adeus nunca enunciado. O texto é gradualmente menos interrompido pelos sinais gráficos, e sua cadência, portanto, fica cada vez mais ágil quanto mais se aproxima do desfecho, e, consequentemente, quanto mais é aumentado o peso subjetivo de um texto que, a princípio, apenas descreve. Também importa pensar, em segundo lugar, que, se a pessoa que em metonímia surge ao final é marcada por um estigma de solidão, o seu estado foi, de certa forma, tanto antecipado quanto reforçado pelo ambiente soturno que povoa a vila anteriormente representada e na qual esse ser se encontra. Vê-se, logo, que o modo ecfrástico escolhido por João Miguel Fernandes Jorge para revelar-nos S. Vicente não é vão: de antemão temos a ambiência diferenciada da vila e, nesse contexto que previamente nos transmite noções de resguardo, aparece, ao final, uma figura destacada e solitária. Em outros trabalhos do autor haverá, também, a presença de seres ora fragilizados, ora isolados - sendo essa uma das tônicas de sua produção poética. Em Não écerto este dizer, temos In den kasernen, poema homoerótico cujo título remete 
8. JORGE. Não é certo este dizer, $\mathrm{p}$. 76-77. a uma canção de Marlene Dietrich, e no qual Edgard Pereira identificará "o fantasma do desejo interdito, tocado pela aura do ascetismo e da paixão, [que] insinua-se com naturalidade, isento de conflitos" (PEREIRA, 1999:352). Nele, também encontramos movimentos ecfrásticos que concorrem para uma definição de um homem e de seu estado de espírito:

Este homem existiu, existe ainda. Não lhe queria ver a cara, a cristaleira

as almofadas com aves do paraíso, as amigas vestidas de roxo. Mas talvez a sua casa seja branca e fria com mobiliário de hospital e dentro de um armário de vidro e ferro em que esperaríamos ver pinças e agulhas, somente uma pequena caixa de alumínio guarda um negro cabelo - de que perdido amante?

Havia um anel nos seus dedo

havia de se lembrar da mãe, da sua mãe com eterna saudade.

Trata-se de um poema extenso, do qual se transcreveu aqui apenas a última parte. Antes desse momento, no texto, nos é narrada uma cena: um homem, "ainda um homem muito novo, num fato escuro", passa defronte a um quar tel e, debruçando-se sobre as grades que cercavam o local, procura despertar a atenção dos soldados que lá se encontram. $\mathrm{O}$ instante, apenas descritivo - e, portanto, ecfrástico, embora com lampejos que denotam caminhos para além do meramente narrativo -, é sucedido, no poema, pelo excerto acima redigido, e que pretende esclarecer quem poderia ser esse homem, ou quais suas pretensões. Os traços de sua personalidade são sugeridos por meio dos objetos que possivelmente povoam sua casa e, por extensão, pertencem ao seu cotidiano: as almofadas com estampas pitorescas, o armário que insinua um "mobiliário de hospital" - e consensualmente a imagem de um hospital evoca doença, deterioração, frieza; portanto, não é fortuita a analogia efetuada pelo autor. Nota-se uma profunda dependência desses objetos, e, portanto, do visual, para que se defina um contorno para esse homem que surge, e, à semelhança do poema anterior, a ambiência, conquistada por meio da ecfrase, viabilizará isso. Aqui, porém, há um novo dado: é a memória do concreto que permanecerá, solidificando a aridez dessa vivência humana. O negro cabelo, guardado em um recipiente de alumínio, pertenceu outrora a um amante perdido, que lá não mais se encontra e que deixou, todavia, uma lembrança concreta de sua passagem; o anel usado aviva a recordação da mãe, atrelada à saudade, pois ela também pertence apenas a um instante anterior e já findado. "Eu penso que a memória entra pelos olhos”, diz Herberto Helder (1995:146), e é justamente o movimento do ver que propicia a rememoração e, junto a ela, a experiência. 
9. MERLEAU-PONTY. Fenomenologia da percepção, p. 3-4.
A ciência não tem e não terá jamais o mesmo sentido de ser que o mundo percebido, pela simples razão de que ela é uma determinação ou uma explicação dele. Eu não sou um "ser vivo", ou mesmo um "homem", ou mesmo uma consciência, com todos os caracteres que a zoologia, a anatomia social ou a psicologia indutiva reconhecem a esses produtos da natureza ou da história - eu sou a fonte absoluta; minha experiência não provém de meus antecedentes, de meu ambiente físico social, ela caminha em direção a eles e os sustenta, pois sou eu quem faz ser para mim (e portanto ser no único sentido que a palavra possa ter para mim) essa tradição que escolho retomar ou este horizonte cuja distância em relação a mim desmoronaria, visto que ela não lhe pertence como uma propriedade, se eu não estivesse lá para percorrê-la com o olhar.'

As figuras de João Miguel Fernandes Jorge olham e esperam. Por meio do uso de certa narratividade, estratégia peculiar e bastante própria da dicção poética desse autor, surge mais do que o enquadramento de uma cena ou local: tem-se uma experiência esboçada, uma construção carregada de subjetividade e localizável através do olhar que as enunciou. Diante disso, é lícito afirmar que o autor, por seu modo literário de produção e, neste, pelas ferramentas das quais se serve, encontra-se dentro da gama de procedimentos ecfrásticos atuais. Para além do conceito sacralizado ao longo dos séculos na história artística e cultural ocidental, Fernandes
Jorge não apenas representa, mas verbaliza: as situações presentes em seus poemas têm a marca não só do descritivo, mas também do sentimento sugerido por detrás da imagem que ali se esboçou. Seja na construção de indivíduos que, por seus gestos ou hábitos, revelam-se profundamente atingidos por uma ausência; seja na composição de um cenário que, por si só, evoca uma instância sombria, transmitindo ao leitor, por extensão, impressões dessa natureza; fato é que a ecfrase serve como plano possibilitador da digressão. A imagem é, certamente, autônoma, no sentido de surgir, clara e nítida, na tessitura textual; mas o modo ecfrástico como ela nos é retratada não se dissocia de uma intencionalidade maior do que apenas a visualização. Concretude e subjetividade, antinomia aparente, aliam-se, portanto, a serviço de uma poética diferenciada e também - talvez por causa dessa oposição, inclusive - impactante.

\section{REFERÊNCIAS}

APOLLINAIRE, Guillaume. II pleut. Disponível em: http://www. atelphot.info/cali.htm. Acesso em: 24/01/2011.

ARISTÓTELES. Arte poética. Disponível em: http://www. dominiopublico.gov.br/pesquisa/DetalheObraForm.do?select action $=\& c o$ obra $=2235$. Acesso em: 18/01/2011 
BENJAMIN, Walter. A obra de arte na era de sua reprodutibilidade técnica. In: Magia e técnica, arte e política: ensaios

sobre literatura e história da cultura. Trad. Sérgio Paulo Rouanet.

São Paulo: Brasiliense, 1994. (Obras escolhidas; volume I).

CONRADO, Maria Fernanda. Ekphrasis e Bildgedicht: processos ekphrásticos nas Metamorfoses de Jorge de Sena. Dissertação de Mestrado em Literatura Comparada. Universidade de Lisboa, 1996.

HELDER, Herberto. Photomatox e vox. Lisboa: Assírio \& Alvim, 1995

HOMERO. Ilíada. Trad. Manoel Odorico Mendes. Ebooks Brasil, 2009.

JORGE, João Miguel Fernandes. Não é certo este dizer. Lisboa: Editorial Presença, 1997.

MERLEAU-PONTY, Maurice. Fenomenologia da percepção. Trad. Carlos Alberto Ribeiro de Moura. São Paulo: Martins Fontes, 2006

PEREIRA, Edgard. Recensão crítica a Não é certo este dizer. In Revista Colóquio Letras, número 153/154, julho de 1999. 